(C) This manuscript version is made available under the CC-BY-NC-ND 4.0 license

https://creativecommons.org/licenses/by-nc-nd/4.0/

https://link.springer.com/article/10.1007/s00216-007-1324-x

\title{
Determination of acetone in seawater using derivatization solid-phase microextraction
}

\author{
Edward D. Hudson \& Kadek Okuda \& Parisa A. Ariya
}

\begin{abstract}
Acetone plays an important role in the chemistry of both the atmosphere and the ocean, due to its potential effect on the tropospheric $\mathrm{HO}_{\mathrm{x}}\left(=\mathrm{HO}+\mathrm{HO}_{2}\right)$ budget, as well as its environmental and health effects. We discuss the development of a mobile, sensitive, selective, economical and facile method for the determination of acetone in seawater. The method consists of derivatizing acetone to its pentafluorobenzyl oxime using 1,2,3,4,5pentafluorobenzylhydroxylamine (PFBHA), followed by solid-phase microextraction (SPME) and analysis by gas chromatography/mass spectrometry (GC/MS). A detection limit of $3.0 \mathrm{nM}$ was achieved. The buffering capacity of seawater imposes challenges in using the method's optimum $\mathrm{pH}$ (3.7) on seawater samples, requiring calibration standards to be made in buffered salt water and the acidification of seawater samples and standards prior to extraction. We employed the technique for analysis of selected surface seawater samples taken on the Nordic seas during the ARK-XX/1 cruise (R.V. Polarstern). An upper limit of 5.5-9.6 nM was observed for acetone in these waters, the first acetone measurements reported for far North Atlantic and Arctic waters.
\end{abstract}

\section{Introduction}

Acetone in the atmosphere is produced by the oxidation of propane and other larger molecular weight hydrocarbons or through direct emission by various species of plants [1,2]. It may also be transferred to the atmosphere from surface seawater [3], where it is thought to be derived from the photodegradation of dissolved organic matter (DOM) [4, 5]; it has also been suggested to be produced directly by certain algae [6] and bacteria [7]. It can be readily exchanged between natural waters and air due to its low molecular weight and volatility. Interest in acetone, along with many other low molecular weight (LMW) carbonyl compounds, has increased due to their potential adverse health effects in drinking water [8]. Moreover, acetone can potentially alter the oxidizing potential of the troposphere through the production of $\mathrm{HO}_{2}[1,9]$. One of the main sources of hydroxyl $(\mathrm{OH})$ radicals in the troposphere is the reaction of water vapour with $\mathrm{O}\left({ }^{1} \mathrm{D}\right)$ (Reactions 1 and 2 ).

$$
\begin{aligned}
\mathrm{O}_{3}+h v(\lambda \leq 320 \mathrm{~nm}) & \rightarrow \mathrm{O}_{2}+\mathrm{O}^{\cdot}\left({ }^{1} \mathrm{D}\right) \\
O^{\prime}\left({ }^{1} \mathrm{D}\right)+\mathrm{H}_{2} \mathrm{O} & \rightarrow 2 \cdot \mathrm{OH}
\end{aligned}
$$

Since the upper troposphere is much dryer than the lower troposphere, the above pathway for the production of hydroxyl radicals is less efficient [10]. In this region of the troposphere, acetone contributes to the production of $\mathrm{HO}_{\mathrm{x}}[10]$. Indeed, by considering acetone photochemistry (photolysis and $\mathrm{OH}$-initiated reactions) in $\mathrm{HO}_{\mathrm{x}}$ calculations, better agreement between experimental and observed values is obtained [11]. Additionally, acetone, along with other LMW carbonyl compounds, can lead to the production of peroxyacetylnitrate (PAN), a reservoir species that allows for long- range transport of $\mathrm{NO}_{\mathrm{x}}[1]$ and thus impacts the atmospheric $\mathrm{HNO}_{3}$ budget. Major sinks of atmospheric acetone are photolysis, oxidation (leading to the production of acetic acid, peroxyacetic acid and methyl glyoxal) and wet deposition [1].

It is not well known whether the oceans are a net source or sink for acetone. Past studies have surmised that the ocean is a net source [3, 12], although more recent studies have obtained data pointing to the contrary [9]. The few reported measurements of acetone in surface seawater show concentrations between 3 and $55 \mathrm{nM}$ [3, 9, 12, 13] with lower concentrations occurring in the bulk water and the higher concentrations occurring in the sea surface microlayer [12]. In the atmosphere the concentration of acetone varies with height and latitude but average mixing ratios are typically $0.3-2.3 \mathrm{ppbv}[1,9,13]$.

Acetone quantification in the atmosphere and the oceans is challenging due to its low concentrations and its 
(C) This manuscript version is made available under the CC-BY-NC-ND 4.0 license

https://creativecommons.org/licenses/by-nc-nd/4.0/

https://link.springer.com/article/10.1007/s00216-007-1324-x

volatility. In recent years, proton transfer reaction mass spectrometry (PTR-MS) [3] and atmospheric pressure chemical ionization mass spectrometry (API-CIMS) [9] have allowed for on-site measurement of acetone in seawater and marine air; however, the instrumentation is expensive and not widely available. Derivatization chromatographic methods are those most frequently found in the literature as they are selective, relatively inexpensive, and widely available. The most commonly reported derivatizing agent for the determination of acetone in both fresh water and seawater is 2,4- dinitrophenylhydrazine (DNPH) [4, 5, 13-16]. The reaction of acetone with DNPH creates a hydrazone, which can be analysed using liquid chromatography (LC) with detection by ultraviolet-visible (UV/Vis) absorbance. Dansyloxyamine (DNSOA) has also been used to derivatize ketones in aqueous samples [17]; the derivatives are separated by LC and quantified by fluorescence. For gas chromatography (GC), derivatization has been accomplished using $O$ - (2,3,4,5,6-pentafluorobenzyl)-hydroxylamine (PFBHA) hydrochloride [8, 18-20] (Reaction 3).

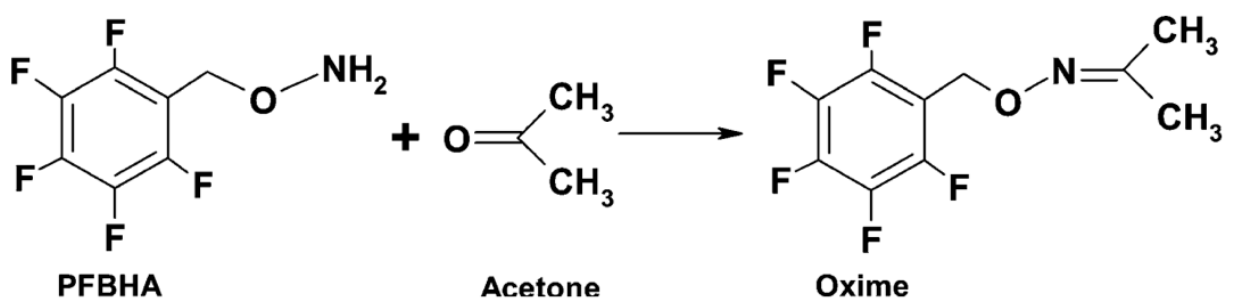

Acetone has also been quantified photometrically by its reaction with vanillin, which produces a yellow-orange dye which absorbs at $430 \mathrm{~nm}$ [21], and by its reaction with alkaline salicylaldehyde [22].

DNPH derivatization can provide low detection limits since it is possible to obtain low blank measurements [16]. However, the use of DNPH also limits the separation techniques available due to the decomposition of several hydrazones at higher temperatures [23]. Derivatization using PFBHA results in the formation of an oxime that is amenable to GC since, unlike hydrazones produced by DNPH derivatization, the oximes do not decompose at the high temperature used for GC [24]. Furthermore, the DNPH derivative must be solvent-extracted or otherwise preconcentrated [16], a step which may be environmentally detrimental (if solvents are needed) or lead to sample contamination.

Solid-phase microextraction (SPME), a method developed by Pawliszyn and co-workers [25, 26], is an attractive alternative for sample preparation, since it requires no solvents and the SPME fibres are readily portable and easy to use. SPME has been used to extract PFBHA derivatives of a range of carbonyl compounds (primarily aldehydes) from both air and water [8, 23, 24].

In the current work, we aimed to develop a routine method for the analysis of acetone in seawater using a SPMEGC-MS technique, which would be sensitive, rapid, facile, environ- mentally benign and use readily available equipment. Todate, SPME has been used to a limited extent to analyse acetone in fresh waters only [8] and the present study represents its first published use for seawater. The use of this technique for analysis of selected surface waters from the Nordic seas, taken during the ARK-XX/1 cruise (R.V. Polarstern, 2004), is herein presented, and advantages and limitations of the technique are discussed.

\section{Experimental Materials}

Acetone (HPLC grade, 99.5+ \%) was purchased from Fisher Scientific (Nepean, ON), and PFBHA hydrochloride from Fluka (St. Louis, MO). Ultrapure water (MilliQ QPAK-1 system, Millipore, Billerica, MA) was used throughout. $\mathrm{NaCl}$ was baked overnight at $450{ }^{\circ} \mathrm{C}$ to remove any organic contaminants. SPME fibres and holders were purchased from Supelco (Bellefonte, PA). Fibres were initially conditioned as per the supplier's instructions, and re-conditioned daily $\left(15 \mathrm{~min}, 250{ }^{\circ} \mathrm{C}\right)$ prior to first use.

Glassware was cleaned by rinsing with ultrapure water, followed by baking overnight in a muffle furnace at $450{ }^{\circ} \mathrm{C}$ 
(C) This manuscript version is made available under the CC-BY-NC-ND 4.0 license https://creativecommons.org/licenses/by-nc-nd/4.0/

https://link.springer.com/article/10.1007/s00216-007-1324-x

to remove organic contaminants. Where this was not possible (e.g. volumetric glassware), it was rinsed with ultrapure water and ethanol and dried overnight at $125^{\circ} \mathrm{C}$.

\section{Solutions, procedure and instrumentation}

PFBHA was prepared daily as a $12 \mathrm{mg} \mathrm{mL}^{-1}(0.0476 \mathrm{M})$ aqueous solution. Blanks and standard solutions for initial tests were made in $3.5 \% \mathrm{w} / \mathrm{w}(0.6 \mathrm{M}) \mathrm{NaCl}$ solution to simulate the salinity of seawater. To additionally simulate the buffering capacity of seawater, buffered salt water solutions were made using $34.78 \mathrm{~g} \mathrm{NaCl}, 0.193 \mathrm{~g} \mathrm{NaHCO}_{3}$ and $0.026 \mathrm{~g} \mathrm{HBO}_{3}$ per $\mathrm{L}$ of solution. This solution was used for calibration purposes (see Results and discussion). Figure 1 shows a schematic of the derivatization and extraction procedure. Derivatizations and extractions were carried out in 20-mL screw-capped vials with Teflon-faced silicone septa. The vials were wrapped in aluminium foil to inhibit any photochemical reactions. Ten-millilitre samples of acetone standards or seawater were used. A $50-\mu \mathrm{L}$ aliquot of PFBHA solution was added to the vials using an Eppendorf pipette and the samples were derivatized with stirring for $2 \mathrm{~h}$, at which point the septum was pre-pierced with a clean syringe needle, $12.7 \mu \mathrm{L}$ $0.2 \mathrm{M} \mathrm{HCl}$ added if necessary (see Results and discussion) and the SPME fibre was inserted into the vial for $30 \mathrm{~min}$ of adsorption. The use of a 30-min adsorption was based on other published studies [8], which indicated that for lower molecular mass PFBHA ketone oximes, maximum adsorption was achieved in 20-50 min, depending on the ketone. Furthermore, it has been shown $[27,28]$ that as long as the adsorption time is constant, full equilibration of the analyte onto the SPME fibre is not necessary for reproducible quantification.

After solid-phase microextraction, the acetone PFBHA oximes were analysed by gas chromatography/mass spectrometry (GC/MS). The fibre was desorbed $\left(250^{\circ} \mathrm{C}\right)$ in splitless mode for 5 min before the split vent was reopened. The fibre was then left in the inlet for an additional $10 \mathrm{~min}$ to ensure that it was fully clean before re-use. GC- MS (HP 6890 GC with 5973 MSD, Agilent, Palo Alto, CA) was performed on an HP 5-MS (5\%-phenylmethylpolysiloxane) column $(30 \mathrm{~m} \times 0.25-\mathrm{mm}$ id $\times 0.25-\mu \mathrm{m}$ film) under the following conditions: splitless injection, He carrier gas $\left(1.5 \mathrm{~mL} \mathrm{~min}{ }^{-1}\right.$, constant flow), injector $250{ }^{\circ} \mathrm{C}$, oven $50{ }^{\circ} \mathrm{C}$ for $2 \mathrm{~min}$, then $5{ }^{\circ} \mathrm{C} \mathrm{min}^{-1}$ to $140{ }^{\circ} \mathrm{C}$, then $20^{\circ} \mathrm{C} \mathrm{min}^{-1}$ to $260^{\circ} \mathrm{C}$ (no final hold), MS in scan mode $(\mathrm{m} / z, 25-400)$, with $70 \mathrm{eV}$ electron ionization, transfer line temperature

$280^{\circ} \mathrm{C}$, MS source temperature $230^{\circ} \mathrm{C}$, quadrupole temperature $150^{\circ} \mathrm{C}$. The acetone PFBHA oxime was identified by comparison of its mass spectrum with previously published electron ionization mass spectra $[18,29]$ and in the NIST 5.0 mass spectral database, and by its presence and retention time in the chromatograms of acetone standards. Peaks were autointegrated using HP Chemstation (version B-01.00) software on the total ion chromatograms.

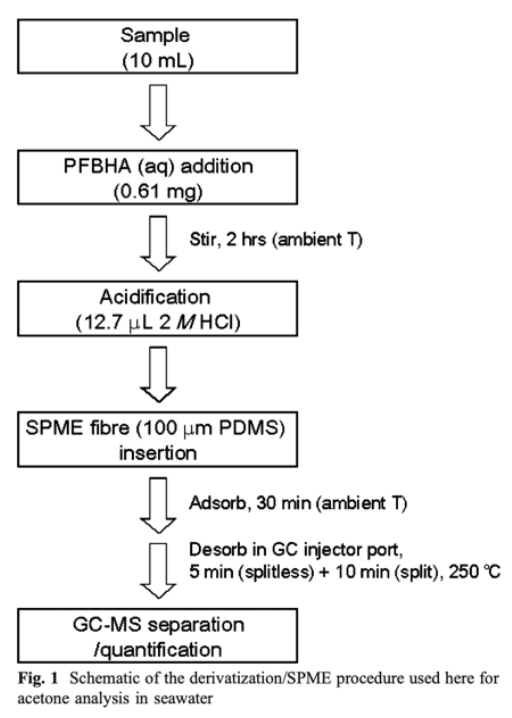


(C) This manuscript version is made available under the CC-BY-NC-ND 4.0 license

https://creativecommons.org/licenses/by-nc-nd/4.0/

https://link.springer.com/article/10.1007/s00216-007-1324-x

\section{Seawater sampling and analysis}

The method was applied to selected samples of surface seawater taken from the Norwegian and Greenland seas during June/July 2004 (cruise ARK-XX/1, RV Polarstern). Samples were taken from 11-m depth by means of a direct inlet line in the ship's keel, and were immediately suction- filtered though a 0.22- $\mu \mathrm{m}$ PTFE membrane filter (across a pressure drop of no greater than 300 mbar). Samples were stored frozen in amber glass bottles with Teflonlined caps (pre-cleaned for EPA Procedure 2 for purgeable volatile organic compounds) (Environmental Sampling and Supply, Oakland, CA) until analysis. Ten-millilitre aliquots of these samples were derivatized and analysed as described previously.

\section{Results and discussion}

Figure 2 shows a typical chromatogram and mass spectrum for the analysis of acetone in seawater as its PFBHA oxime. Throughout this study, reported peak areas are from the integration of the total ion chromatogram.

\section{Comparison of SPME fibres (adsorbants)}

Derivatized and underivatized acetone were compared on three different SPME fibres: 100- $\mu \mathrm{m}$ polydimethylsiloxane (PDMS), $65-\mu \mathrm{m}$ polydimethylsiloxane/divinylbenzene (PDMS/DVB), and 75- $\mu \mathrm{m}$ carboxen/polydimethylsiloxane (CAR/PDMS) (Fig. 3a). Underivatized acetone $(0.27 \mu \mathrm{M})$ was only detected by the CAR/PDMS fibre. The peak for underivatized acetone on this fibre was small and eluted before the split vent had closed, where the baseline of the total ion chromatogram was considerably higher. By comparison, the peak due to the acetone oxime on the CAR/PDMS fibre was larger, exhibited less tailing and eluted later (after the re-opening of the split vent), resulting in more reliable integration. All three fibres detected the acetone oxime at this same concentration $(0.27 \mu \mathrm{M})$, whereas only the CAR/PDMS fibre detected underivatized acetone. We thus concluded that derivatizing the acetone had the ability to provide a superior method for acetone analysis.
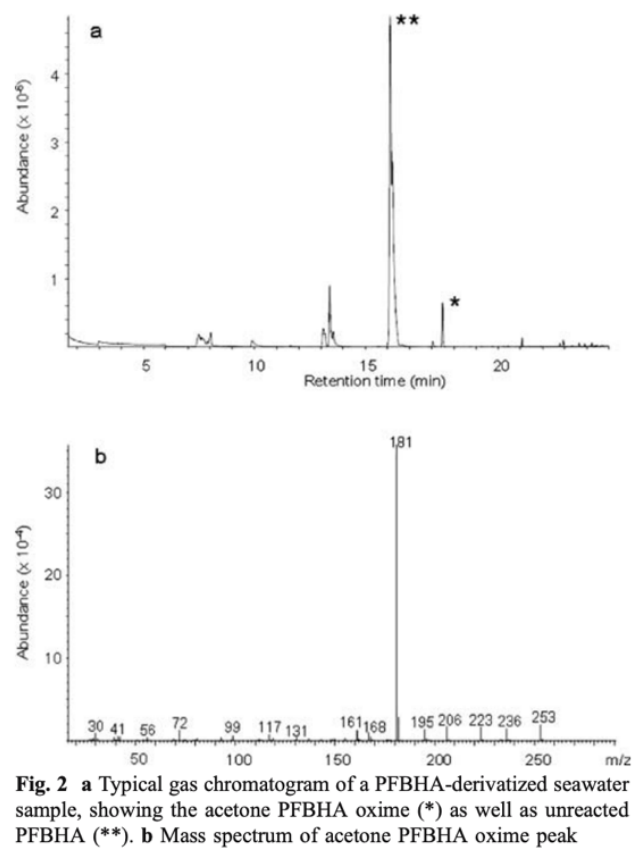
(C) This manuscript version is made available under the CC-BY-NC-ND 4.0 license https://creativecommons.org/licenses/by-nc-nd/4.0/

https://link.springer.com/article/10.1007/s00216-007-1324-x
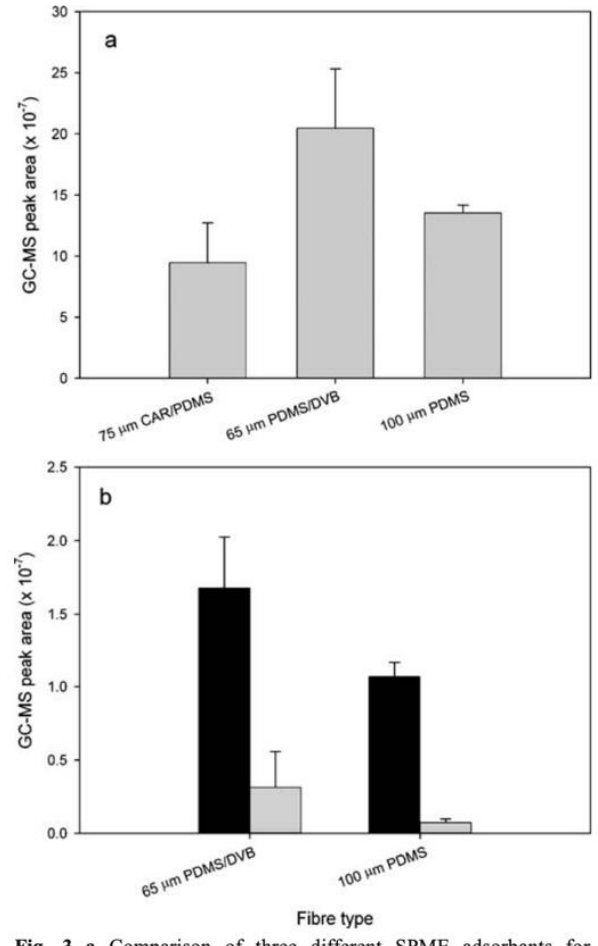

Fig. 3 a Comparison of three different SPME adsorbants for sensitivity and reproducibility for acetone PFBHA oxime $(0.27 \mu \mathrm{M}$ acetone), mean $\pm \mathrm{SD}, n=2$. b Further comparison of the two best adsorbants in a.Black bars $67 \mathrm{nM}$ acetone, grey bars $13 \mathrm{nM}$ acetone, mean $\pm \mathrm{SD}, n=3$

Figure 3a shows the acetone oxime peak areas on all three fibres, based on duplicate measurements. The measurement on the CAR/PDMS fibre was the least sensitive and least reproducible (34\% RSD) and consequently this fibre was not employed in any further experiments. Furthermore, Fig. 3a indicates that the PDMS/DVB fibre shows greater sensitivity while the PDMS fibre shows greater reproducibility under these conditions $(0.27 \mu \mathrm{M}$ acetone, derivatized). Further comparisons between the PDMS/DVB and PDMS fibre were performed, using acetone concentrations of $67 \mathrm{nM}$ and $13 \mathrm{nM}$, in triplicate. Again, the PDMS fibre showed greater reproducibility and the PDMS/DVB fibre showing better sensitivity (Fig. 3b). The PDMS fibre was thus selected for future experiments owing to its greater reproducibility coupled with its adequate significant sensitivity.

\section{Sample and headspace volume}

While the fibre comparisons were done using a sample size of $10 \mathrm{~mL}$, a comparison was performed between 10-mL and $20-\mathrm{mL}$ sample volumes to determine if the headspace had significant effects. For duplicate samples containing $0.34 \mu \mathrm{M}$ acetone, the blank-corrected acetone oxime peak areas for the two volumes were $5.7 \%$ greater for the 20 $\mathrm{mL}$ than for the $10-\mathrm{mL}$ sample volume. A $10-\mathrm{mL}$ sample size was used for all other experiments. This smaller sample size reduced the amount of sample and derivatizing agent required while still providing substantial peak areas for acetone analysis.

\section{Effects of pH and buffering in seawater}

To determine the optimum $\mathrm{pH}$ for the SPME extraction step, the $\mathrm{pH}$ of derivatized $34 \mathrm{nM}$ acetone solutions was modified immediately prior to extraction using small quantities of trace metal grade hydrochloric acid $(2 \mathrm{M}$ or $0.2 \mathrm{M}$ ) or ammonia $(0.08 \mathrm{M})$. These 40 - to $50-\mu \mathrm{L}$ additions changed the volume negligibly. The unmodified solutions of PFBHA and the acetone oxime consistently produced a pH of 3.7 \pm 0.1 . Over the $\mathrm{pH}$ range tested, the $\mathrm{pH}$ of the unmodified solution ( $\mathrm{pH}$ 3.7) was optimal both in terms of peak area and reproducibility (3\% RSD) (Fig. 4a), although 
(C) This manuscript version is made available under the CC-BY-NC-ND 4.0 license https://creativecommons.org/licenses/by-nc-nd/4.0/

https://link.springer.com/article/10.1007/s00216-007-1324-x

the peak areas did not differ greatly over the range studied. This contrasts with the work of Bao et al. [8], who acidified the sample between derivatization and extraction, although they did not explain the purpose of this procedure. Basic $\mathrm{pH}$ values were not tested because of the difficulty in obtaining them reproducibly.

It was subsequently noted that the final $\mathrm{pH}$ of seawater after derivatization and extraction was between 7 and 8 , in contrast to that of salt water standards ( $\mathrm{pH} 3.7$, above). This is due to the buffering of seawater by the carbonate and, to some extent borate, systems. Thus, the optimum $\mathrm{pH}$ for SPME extraction ( $\mathrm{pH}$ 3.7) could not be achieved on seawater without modification. We found that the addition of $12.7 \mu \mathrm{L}$ of $0.2 \mathrm{M} \mathrm{HCl}$ brought the $\mathrm{pH}$ of seawater and PFBHA to $3.7 \pm 0.1$ (Table 1), and all seawater samples were therefore acidified this way immediately prior to insertion of the SPME fibre for extraction. For calibration purposes, a buffered salt water was devised (as described in the Experimental section) with which we aimed to replicate the salinity and buffering capacity of seawater. The $\mathrm{pH}$ behaviour of this solution on addition of PFBHA. $\mathrm{HCl}$ and of $0.2 \mathrm{M} \mathrm{HCl}$ was the same as that of natural seawater (Table 1). Tests on seawater from $75.00^{\circ} \mathrm{N}, 16.06^{\circ} \mathrm{W}$ (site 4, Table 2), derivatized as described previously, demonstrated that the acidification step led to more of the acetone oxime being extracted and detected (Fig. 4b).
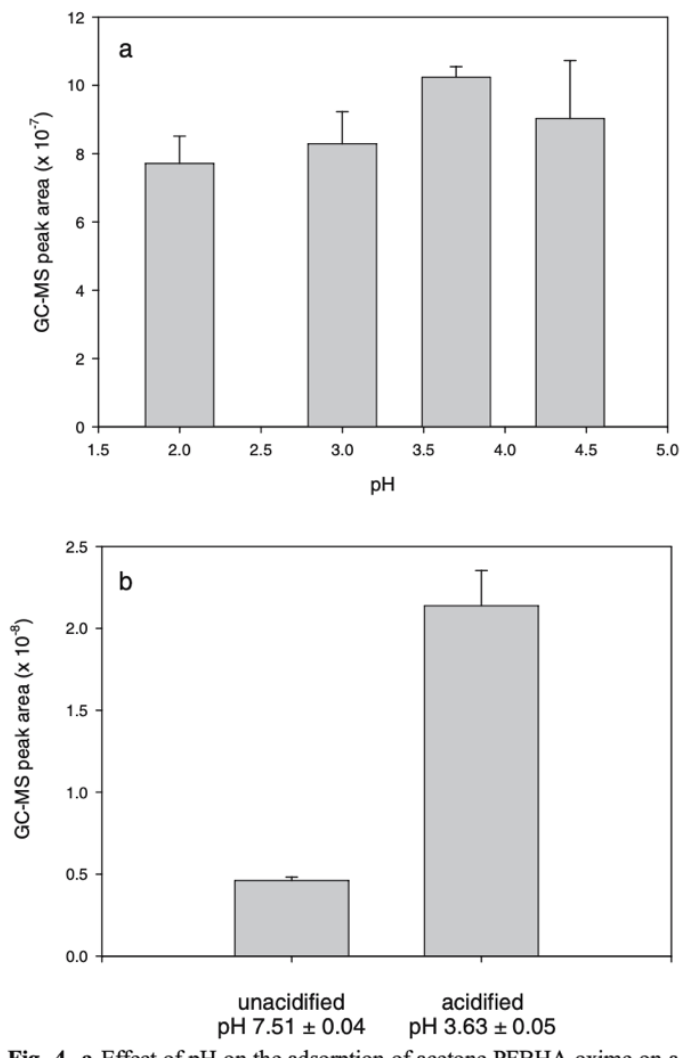

Fig. 4 a Effect of $\mathrm{pH}$ on the adsorption of acetone PFBHA oxime on a $100 \mu \mathrm{m}$ PDMS SPME fibre. b Effect on seawater $\left(75.00^{\circ} \mathrm{N}, 16.06^{\circ} \mathrm{W}\right)$ of acidification prior to SPME extraction. Mean $\pm \mathrm{SD}, n=2$ (in both plots)

\section{Acetone in salt water blanks}

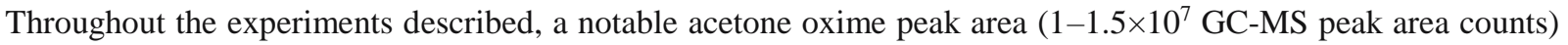
was detected in blanks (buffered or unbuffered salt water), as well as in standards and samples. We aimed to identify the source of acetone in these blanks to see if it could be 
(C) This manuscript version is made available under the CC-BY-NC-ND 4.0 license https://creativecommons.org/licenses/by-nc-nd/4.0/

https://link.springer.com/article/10.1007/s00216-007-1324-x

Table $1 \mathrm{pH}$ behaviour of surface seawater from $75.00^{\circ} \mathrm{N}, 16.06^{\circ} \mathrm{W}$ and of the salt water solution buffered by $\mathrm{NaHCO}_{3}$ and $\mathrm{HBO}_{3}$

\begin{tabular}{lll}
\hline & Seawater & $\begin{array}{l}\text { Buffered salt } \\
\text { water }\end{array}$ \\
\hline $\begin{array}{l}\text { Original } \mathrm{pH} \\
\mathrm{pH} \text { after addition of } 50 \mu \mathrm{L} \text { PFBHA }\end{array}$ & $7.83 \pm 0.05$ & $7.66 \pm 0.05$ \\
solution & & $7.00 \pm 0.04$ \\
$\mathrm{pH}$ after further addition of $12.7 \mu \mathrm{L}$ & $3.59 \pm 0.08$ & $3.75 \pm 0.09$ \\
$0.2 \mathrm{M} \mathrm{HCl}$ solution & & \\
\hline
\end{tabular}

Mean \pm SD, $n=2$. The $\mathrm{pHs}$ obtained after acidification did not differ significantly at the $5 \%$ confidence level

Table 2 Acetone concentrations in surface waters from selected sites in the Nordic seas

\begin{tabular}{ll}
\hline Location, sampling date & $\begin{array}{l}\text { Measured [acetone] } / \mathrm{nM} \\
(\operatorname{mean} \pm \mathrm{SE}, n=2)\end{array}$ \\
\hline
\end{tabular}

1. $68.30^{\circ} \mathrm{N}, 9.46^{\circ} \mathrm{E}, 19$ June $2006 \quad 6.7 \pm 3.6$

2. $75.00^{\circ} \mathrm{N}, 5.77^{\circ} \mathrm{E}, 25$ June $2006 \quad 6.3 \pm 3.6$

3. $75.00^{\circ} \mathrm{N}, 1.80^{\circ} \mathrm{E}, 26$ June $2006 \quad 9.6 \pm 3.6$

4. $75.00^{\circ} \mathrm{N}, 16.06^{\circ} \mathrm{W}, 3$ July $2006 \quad 5.5 \pm 3.6$

5. $79.34^{\circ} \mathrm{N}, 5.92^{\circ} \mathrm{W}, 12$ July 2006 BDL

Location numbers refer to Fig. 7

$B D L$ below detection limit

reduced, since method detection limits are currently con- strained by this blank measurement. We considered two possibilities: that acetone in the blanks was coming from the laboratory air during preparation or transfer of standards and samples, or that it was present in the purified water used to make the salt water solutions (and therefore the standards).

On the assumption that the water was the source of this contamination, further purification was attempted. A second purification of the water, already purified as described, was undertaken using a Milli-Q Simplicity 185 water purifier fitted with a Simpak 2 cartridge and a final UV oxidation cell (Millipore, Billerica, MA), and salt water was prepared using this re-purified water. Further batches of salt water solution, prepared using the original (QPAK-1) purified water, were subjected to UV oxidation to attempt to destroy any remaining organic contaminants. Solutions were enclosed in a 3-L cylindrical glass vessel fitted with a 7-cm circular quartz window and irradiated with a $75-\mathrm{W}$ mercury arc lamp $\left(\lambda \lambda_{\max } 254 \mathrm{~nm}\right.$; Oriel, Stratford, CT). As a final treatment, the solution and the headspace were sparged/purged with UHP helium prior to irradiation.

Further purification using the Simpak 2 cartridge/final UV oxidation cell did not result in a significantly different (Students' $t$-test, $P<0.05$ ) acetone oxime peak area in the blanks (Fig. 5, a vs. b). Batchwise UV irradiation resulted in higher acetone oxime peak areas in the blanks (Fig. 5, c-e) than in non-irradiated salt water, even after $71 \mathrm{~h}$ of irradiation (Fig. 5, d), or after purging/sparging with UHP helium and $17 \mathrm{~h}$ of irradiation (Fig. 5, e). These results 
(C) This manuscript version is made available under the CC-BY-NC-ND 4.0 license https://creativecommons.org/licenses/by-nc-nd/4.0/

https://link.springer.com/article/10.1007/s00216-007-1324-x

suggest de novo formation of acetone from UV oxidation of higher molecular weight contaminants, rather than acetone destruction, although this conclusion is tentative due to limited experimentation.

In an attempt to prevent contamination of samples via laboratory air, the use of acetone anywhere in the laboratory was avoided on days when any of the experiments described in this work were performed. However, to further investigate this air as a potential contamination source, all operations during the preparation, dispensing and derivatization of buffered salt water blanks (except the weighing of the dry salts) were performed in a Plexiglas chamber of ca. $1-\mathrm{m}^{3}$ volume with a front face of heavy, flexible, clear polyethylene and flushed with UHP helium, or later, UHP nitrogen. This included enclosing the Milli-Q Simplicity 185 water purifier in the chamber; however, the 2-h stirring and 30-min SPME extraction steps, during which time the samples were isolated from the laboratory atmosphere in vials, were still done on the open bench. In each case, acetone oxime peak areas in buffered salt water solutions prepared in these clean atmospheres did not differ significantly $(P<0.05)$ from those in buffered salt water solutions prepared contemporaneously on the laboratory bench. These results suggest that the laboratory air was not the source of traces of acetone in blanks.

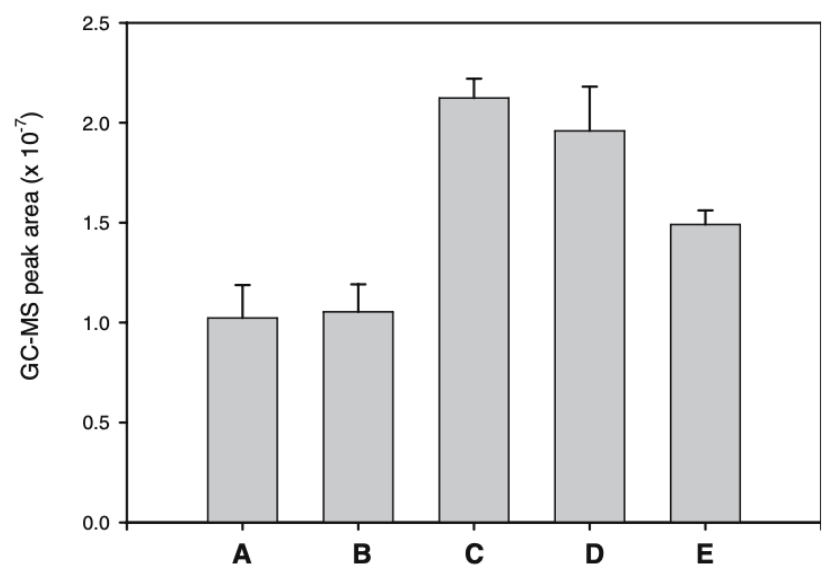

Fig. 5 Acetone PFBHA oxime peak areas in salt water blanks prepared with different purified water sources or irradiated: $A$ salt water prepared with milliQ (QPAK-1) water, $B$ salt water prepared after further purification of MilliQ water (Simpak 2, UV oxidation), $C$ water from $A$, UV-irradiated for $20 \mathrm{~h}, D$ water from $A$, irradiated for $71 \mathrm{~h}, E$ water from $A$, sparged with UHP helium and irradiated under helium, $17 \mathrm{~h}$. Mean $\pm \mathrm{SD}, n=2$

\section{Derivatization time}

Bao et al. [8] report that, for the PFBHA derivatization of ketones (in contrast to aldehydes) in fresh waters, longer derivatization times (up to $20 \mathrm{~h}$ ) are needed. Other studies also indicate an increasing yield of PFBHA oximes with longer reaction time for selected ketones, including acetone [18, 19]. We wished to ascertain whether the length of derivatization could be shortened to a more practical time without sacrificing sensitivity and reproducibility, as well as to determine the stability of the acetone PFBHA oxime over time. A series of 10 -mL aliquots of surface seawater from $75.00^{\circ} \mathrm{N}, 16.06^{\circ} \mathrm{W}$ (site 4, Table 2) was derivatized for differing lengths of time before being acidified, adsorbed and analysed as described previously. The peak area from the oxime increased in a near-linear fashion $\left(r^{2}=0.93\right)$ over the first $25 \mathrm{~h}$ of derivatization. The increase appeared to continue for up to $66 \mathrm{~h}$, although with more scatter in the data $\left(r^{2}=0.86\right)$; the peak area measured after $68 \mathrm{~h}$ was less than that at $66 \mathrm{~h}$. Earlier experiments with acetone standards in $\mathrm{NaCl}$ solution had indicated a more rapid degradation or loss of the oxime once $50 \mathrm{~h}$ had elapsed. The data suggested that better sensitivity could be obtained using a longer derivatization time, but at a cost of reproducibility, and that sensitivity after a relatively short derivatization time was adequate. Hence, all further samples were derivatized for $2 \mathrm{~h}$.

\section{Calibration}

Given previously reported acetone concentrations in sea- water $[3,9,12,13]$, we analyzed calibration standards over 
(C) This manuscript version is made available under the CC-BY-NC-ND 4.0 license https://creativecommons.org/licenses/by-nc-nd/4.0/

https://link.springer.com/article/10.1007/s00216-007-1324-x

the range 4.3-150 nM, made in buffered salt water. Calibration samples were analysed with two different SPME fibres of the same type (100- $\mu \mathrm{m}$ PDMS), one for each calibration curve, on separate days (Fig. 6). For both curves, $r^{2}$ exceeded 0.99. The two different SPME fibres gave calibration curves with different slopes. This may reflect differences in age and degree of use, and underlines the need to use a single fibre when comparing samples and standards. For the upper calibration curve in Fig. 6, the calculated detection limit (three times the standard deviation of the blank divided by the slope of the calibration curve) was $3.0 \mathrm{nM}$. This same SPME fibre was used in seawater analysis. Bao et al. [8] reported a detection limit of

$1.4 \mathrm{nM}$ for acetone in fresh water by PFBHA derivatization followed by SPME, although that study employed an electron capture detector, highly sensitive to the polyfluorinated derivative, as the GC detector.

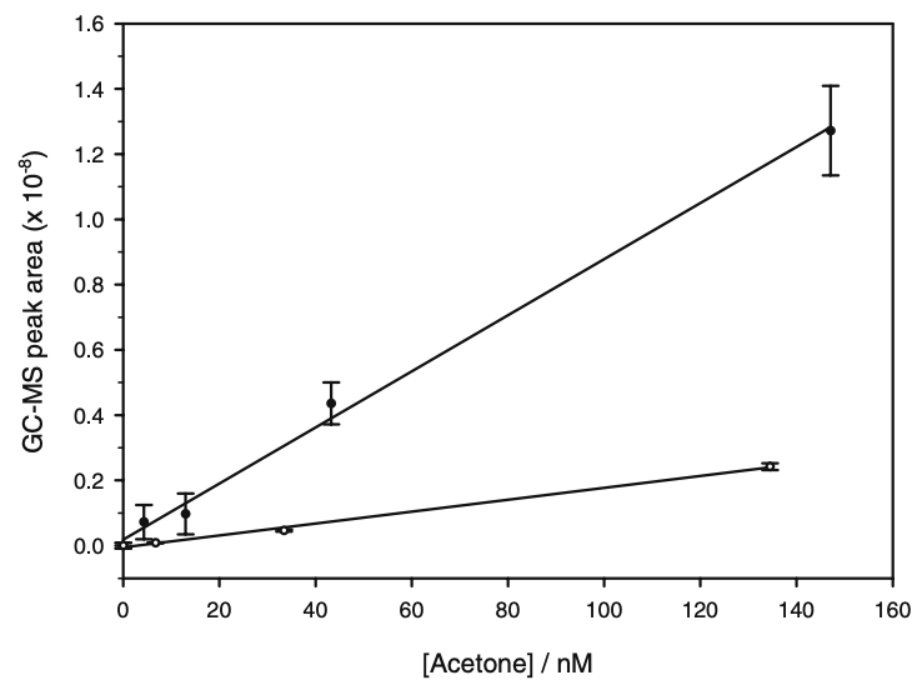

Fig. 6 Calibration curves for acetone, as its PFBHA oxime, using $100-\mu \mathrm{m}$ PDMS SPME fibres. The upper and lower curves represent calibrations performed on different days and with different fibres. Error bars are standard deviations

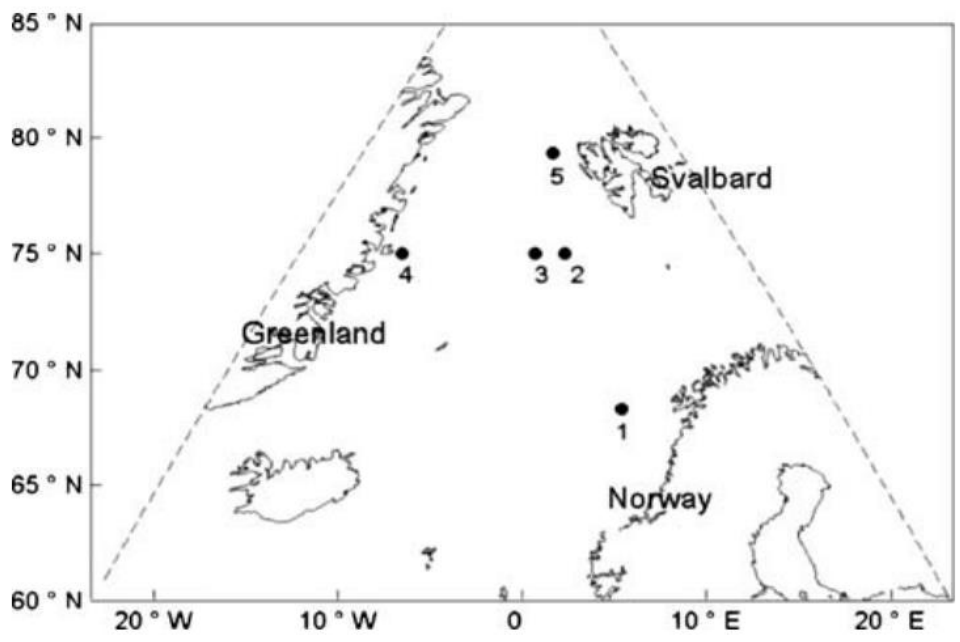

Fig. 7 Sampling locations of seawater samples reported in Table 2. All samples were taken at $11-\mathrm{m}$ depth. Map is a sinusoidal equal-area (Sanson-Flamsteed) projection 
(C) This manuscript version is made available under the CC-BY-NC-ND 4.0 license

https://creativecommons.org/licenses/by-nc-nd/4.0/

https://link.springer.com/article/10.1007/s00216-007-1324-x

\section{Analysis of seawater}

Acetone concentrations in selected surface seawater are reported in Table 2, and range from 5.5 to $6.9 \mathrm{nM}$. These are the first acetone concentrations reported for far North Atlantic and Arctic waters (Fig. 7). They are lower than the mean reported for the tropical Atlantic $(17.6 \mathrm{nM})$ [3], although within the range of values reported from both the Atlantic and Pacific $(<3-70 \mathrm{nM})[3,9,12]$. The values are also surprisingly uniform, given the area covered, and lower than might be expected given that sampling took place during the season of greatest biological activity, that algal blooms were observed in the waters traversed by the cruise at the time of sampling, and that certain marine algal and bacterial species are known to produce acetone [6, 7]. Furthermore, Whelan et al. [6] noted that filtering the sample can lead to additional acetone formation or release. Thus, the reported values must be considered upper limits, and concentrations in these waters may be lower still. Analysis of a greater number of samples from this area should elucidate the degree of uniformity, or patterns of variability, in acetone concentrations. Based on the current data set, it is not yet possible to ascertain whether surface waters of the Nordic seas are a source or sink of tropospheric acetone, especially considering the paucity of atmospheric acetone measurements for these regions and further considering that acetone may be 18 times more concentrated in the sea surface microlayer than in underlying bulk seawater [12].

\section{Conclusions}

A variety of factors which affect the SPME analysis of acetone in seawater (SPME adsorbent, $\mathrm{pH}$, derivatization time) have been identified, explored and optimized. While further work is needed to improve detection limits by lowering signals in salt water blanks, results to date indicate a promising, low-cost, easy-to-use method that could be applied to large-scale studies of acetone and other carbonyl compounds in seawater. Initial results from the analysis of North Atlantic/Arctic surface seawater indicate an upper limit of 5.5-9.6 nM acetone in these waters. More extensive analysis of Nordic sea surface waters will better indicate the spatial pattern of acetone concentrations. SPME fibres are readily portable, and no solvents are required. Therefore, through the use of portable GC and/or GC-MS instrumentation (e.g. see refs. [30, 31] ) the method could be used at sea, thus avoiding the risk of contamination or artifacts associated with the filtration, transport or storage of seawater samples.

\section{Acknowledgements}

We thank the Natural Sciences and Engineering Research Council (NSERC) and the Canada Foundation for Climate and Atmospheric Sciences (CFCAS) for financial support, and the scientists and crew of the R.V. Polarstern for assistance with sampling during the ARK-XX/1 cruise.

\section{References}

1. Singh HB, Ohara D, Herlth D, Sachse W, Blake DR, Bradshaw JD, Kanakidou M, Crutzen PJ (1994) J Geophys Res Atmos 99: 1805 1819

2. Kirstine W, Galbally I, Ye YR, Hooper M (1998) J Geophys Res Atmos 103:10605-10619

3. Williams J, Holzinger R, Gros V, Xu X, Atlas E, Wallace DWR (2004) Geophys Res Lett 31

4. Mopper K, Stahovec WL (1986) Mar Chem 19:305-321

5. Kieber RJ, Zhou XL, Mopper K (1990) Limnol Oceanogr 35:1503-1515

6. Whelan JK, Tarafa ME, Hunt JM (1982) Nature 299:50-52

7. Nemecek-Marshall M, Wojciechowski C, Kuzma J, Silver GM, Fall R (1995) Appl Environ Microbiol 61:44-47

8. Bao ML, Pantani F, Griffini O, Burrini D, Santianni D, Barbieri K (1998) J Chromatogr A 809:75-87

9. Marandino CA, De Bruyn WJ, Miller SD, Prather MJ, Saltzman ES (2005) Geophys Res Lett 32

10. Singh HB, Kanakidou M, Crutzen PJ, Jacob DJ (1995) Nature 378:50-54

11. Wennberg PO, Hanisco TF, Jaegle L, Jacob DJ, Hintsa EJ, Lanzendorf EJ, Anderson JG, Gao RS, Keim ER, Donnelly SG, Del Negro LA, Fahey DW, McKeen SA, Salawitch RJ, Webster CR, May RD, Herman RL, Proffitt MH, Margitan JJ, Atlas EL, Schauffler SM, Flocke F, McElroy CT, Bui TP (1998) Science 279:49-53

12. Zhou XL, Mopper K (1997) Mar Chem 56:201-213

13. Zhou XL, Mopper K (1990) Environ Sci Technol 24:1864-1869

14. Ogawa I, Fritz JS (1985) J Chromatogr 329:81-89

15. Selim S (1977) J Chromatogr 136:271-277

16. Kieber RJ, Mopper K (1990) Environ Sci Technol 24:1477-1481 
(C) This manuscript version is made available under the CC-BY-NC-ND 4.0 license

https://creativecommons.org/licenses/by-nc-nd/4.0/

https://link.springer.com/article/10.1007/s00216-007-1324-x

17. Houdier S, Legrand M, Boturyn D, Croze S, Defrancq E, Lhomme J (1999) Anal Chim Acta 382:253-263

18. Glaze WH, Koga M, Cancilla D (1989) Environ Sci Technol 23:838-847

19. Lelacheur RM, Sonnenberg LB, Singer PC, Christman RF, Charles MJ (1993) Environ Sci Technol 27:2745-2753

20. Yamada H, Somiya I (1989) Ozone Sci Eng 11:127-141

21. Amlathe S, Gupta VK (1990) Analyst 115:1385-1387

22. Teshima N, Li JZ, Toda K, Dasgupta PK (2005) Anal Chim Acta 535:189-199

23. Tsai SW, Chang TA (2002) J Chromatogr A 954:191

24. Tsai SW, Chang CM (2003) J Chromatogr A 1015:143-150

25. Lord H, Pawliszyn J (2000) J Chromatogr A 885:153-193

26. Lord HL, Pawliszyn J (1998) LC GC-Mag Sep Sci 136:1-46 27. Ai J (1997) Anal Chem 69:1230-1236

28. Potter DW, Pawliszyn J (1994) Environ Sci Technol 28:298-305

29. Ojala M, Kotiaho T, Siirila J, Sihvonen ML (1994) Talanta 41:1297-1309

30. Smith PA, Sng MT, Eckenrode BA, Leow SY, Koch D, Erickson RP, Lepage CRJ, Hook GL (2005) J Chromatogr A 1067:285

31. Santos FJ, Galceran MT (2002) TRAC-Trend Anal Chem 21:672-685 
(C) This manuscript version is made available under the CC-BY-NC-ND 4.0 license https://creativecommons.org/licenses/by-nc-nd/4.0/

https://link.springer.com/article/10.1007/s00216-007-1324-x 